\title{
Short oestrous cycles in sheep during anoestrus involve defects in progesterone biosynthesis and luteal neovascularisation
}

\author{
H M Brown ${ }^{1,+}$, C Fabre Nys ${ }^{1}$, J Cognié ${ }^{1}$ and R J Scaramuzzi ${ }^{1,2}$ \\ ${ }^{1}$ UMR Physiologie de la Reproduction et des Comportements, UMR 6175, INRA-CNRS-Université de Tours-Haras \\ Nationaux, 37380 Nouzilly, France and ${ }^{2}$ Department of Comparative Biomedical Sciences, Royal Veterinary College, \\ Hawkshead Lane, South Mimms, Hertfordshire AL9 7TA, UK
}

Correspondence should be addressed to R J Scaramuzzi; Email: rex.scaramuzzi@orange.fr

${ }^{\dagger} \mathrm{H}$ M Brown is now at School of Paediatrics and Reproductive Health, Robinson Institute, University of Adelaide, Adelaide, South Australia 5005, Australia

\begin{abstract}
Anoestrous ewes can be induced to ovulate by the socio-sexual, 'ram effect'. However, in some ewes, the induced ovulation is followed by an abnormally short luteal phase causing a so-called 'short cycle'. The defect responsible for this luteal dysfunction has not been identified. In this study, we investigated ovarian and uterine factors implicated in male-induced short cycles in anoestrous ewes using a combined endocrine and molecular strategy. Before ovulation, we were able to detect a moderate loss of thecal expression of steroid acute regulatory protein (STAR) in ewes that had not received progesterone priming (which prevents short cycles). At and following ovulation, we were able to identify a significant loss of expression of genes coding key proteins involved in the biosynthesis of progesterone (STAR, CYP11A1 and HSD3B1 (HSD3B)) as well as genes coding proteins critical for vascular development during early luteal development (VEGFA and KDR (VEGFR2)), suggesting dysfunction in at least two pathways critical for normal luteal function. Furthermore, these changes were associated with a significant reduction of progesterone production and luteal weight. Additionally, we cast doubt on the proposed uterus-mediated effect of prostaglandin F2 $\alpha$ (PGF2 $\alpha$ ) as a cause of short cycles by demonstrating the dysregulation of luteal expression of the PGF receptor, which mediates the luteal effects of PGF $2 \alpha$, and by finding no significant changes in the circulating concentrations of PGFM, the principal metabolite of PGF2 $\alpha$ in ewes with short cycles. This study is the first of its kind to examine concurrently the endocrine and molecular events in the follicular and early luteal stages of the short cycle.
\end{abstract}

\section{Free French abstract}

A French translation of this abstract is freely available at http://www.reproduction-online.org/content/147/3/357/suppl/DC1

Reproduction (2014) 147 357-367

\section{Introduction}

Consumer-driven, global demand for sustainable products has highlighted the need for hormone-free meat and dairy production, and the development of production systems that satisfy this demand has become a priority for research in animal production. The current interest in 'clean, green and ethical' farming (Martin et al. 2004, Martin \& Kadokawa 2006) that sets out to develop economically viable production systems that do not use exogenous hormones to manipulate reproduction is one response to this consumer demand.

Current methods for the hormonal manipulation of sheep reproduction during the seasonal anoestrous include the use of synthetic progestagens and hormones with gonadotrophic activity (Gordon 1997). However, research into alternative techniques to manipulate reproduction that are more 'natural' is expanding. One of these 'natural' methods applicable to sheep production systems is the 'ram effect', an established method for mating ewes outside the natural breeding season (Knight et al. 1975). The exposure of anoestrous ewes to rams induces a short-term increase in the pulsatility of luteinising hormone (LH), inducing, in turn, the LH surge-induced ovulatory cascade some 2 days later (Pearce \& Oldham 1988). There is a poorly understood variability in the response to the 'ram effect' that limits its effectiveness and inhibits its uptake by the industry (Ungerfeld et al. 2004). Additionally for unknown reasons, luteal failure can occur and a short 
cycle follows in a proportion of ewes stimulated with the 'ram effect', which results in two peaks of lambing (Pearce et al. 1985) and is an additional impediment to industry uptake. While our understanding of the breed-, season- and stress-related mechanisms that contribute to variability in the response to the 'ram effect' continues to improve (Chanvallon et al. 2011), the physiological mechanisms surrounding short cycles remain elusive.

Normal ovarian function in the breeding season and reproductive success rely on the precise feedback regulation of the hypothalamic-pituitary-gonadal axis, and minor disturbance to this pathway is likely to result in failure of normal ovarian function. Ordinarily, during the sheep breeding season, an oestrous cycle lasts 17-19 days with a short follicular phase of 3-4 days followed by a longer luteal phase. Loss of luteal progesterone secretion at the end of the oestrous cycle occurs via uterine secretion of prostaglandin $F 2 \alpha$ (PGF2 $\alpha$ ), which is delivered locally from the uterine vein to the adjacent ovarian artery (Land et al. 1976, Weems et al. 1992). Uterine secretion of PGF2 $\alpha$ to initiate luteolysis begins around day 12 in ewes (Weems et al. 2006). During anoestrous, normal ovarian function is curtailed, and understandably, there are little published data concerning ovarian function at this time. However, folliculogenesis continues and antral follicles are present in the ovaries of anoestrous ewes (Cahill 1981). Follicles in anoestrous ovaries can be induced to ovulate with exogenous gonadotrophins and also in the ewes by the socio-sexual stimulus of the 'ram effect', which presumably by central mechanisms stimulates the secretion of gonadotrophin-releasing hormone $(\mathrm{GNRH})$, leading to an increased pulsatile secretion of LH (Martin et al. 1986) that initiates the cascade of ovarian events leading to ovulation (Chemineau et al. 2006).

Little is known about the mechanisms associated with a ram-induced luteal phase at a molecular level, but in a variable proportion of the induced ewes, the corpus luteum $(\mathrm{CL})$ fails to develop normally. These so-called short cycles last 3-4 days and the concentration of progesterone rarely exceeds $1 \mathrm{ng} / \mathrm{ml}$ (Ungerfeld et al. 2004). Logically, they are either the result of a failure of the process of luteinisation and neovascularisation of the follicular remnants or the result of premature luteolysis. Recently, Chemineau et al. (2006) have proposed a series of sequential events for short cycles in sheep and goats. This model proposes poor follicular quality, leading to an insufficient proportion of large luteal cells resulting in lower progesterone production, all culminating in premature PG-stimulated luteolysis. There is evidence to suggest that uterine PG is involved in short cycles (Acritopoulou \& Haresign 1980, Chemineau et al. 1993, Lassoued et al. 1997), lending support to this hypothesis. There is virtually no published evidence to support the failure of the luteinisation model; nevertheless, it remains an obvious and attractive alternative model. It is now known that short cycles are not associated with premature LH surges as was once suggested (Pearce et al. 1985, Chanvallon et al. 2011).

There is ample evidence from a number of natural and experimental models that exposure to progesterone during follicular growth facilitates and may even be essential for normal luteinisation. Curiously, a single injection of $20 \mathrm{mg}$ of progesterone 24-48 h before the 'ram effect' completely prevents the occurrence of short cycles (Martin et al. 1981, 1986, Ungerfeld et al. 2004). The mechanism of this effect is not known. It has been suggested that the effect of progesterone is mediated by the uterus (Chemineau et al. 2006), but equally the effect could be mediated by the follicle. Many groups have explored the short-, mediumand long-term endocrinological profiles in response to the 'ram effect' during anoestrous, but in spite of this, they have failed to advance the general understanding of the underlying cause of the luteal failure that frequently follows a ram-induced ovulation.

This paper examines potential ovarian and endocrine factors associated with the short cycle. Using a wellcharacterised experimental model, we describe the endocrinological disturbances associated with the short oestrous cycle. We also analysed, using molecular biology, a number of pathways known to be involved in luteinisation, progesterone synthesis and secretion, and luteolysis to improve our understanding of the pathophysiology of luteal dysfunction. Thus, this paper provides some initial physiological insights and reports molecular characterisation of the mechanisms governing the malfunction of the $\mathrm{CL}$ during the short cycle, particularly with respect to the secretion of progesterone and the developing vasculature of the CL.

\section{Materials and methods}

\section{General}

This study was carried out in accordance with French and European regulations on the care and welfare of animals in research, and ethical approval was obtained where required. lle-de-France ewes (aged 3-6 years) were obtained from the experimental flock at INRA (Nouzilly, France). The animals were housed under cover but in natural photoperiod (latitude (DMS): $47^{\circ} 32^{\prime} 60 \mathrm{~N}$; longitude (DMS): $0^{\circ} 45^{\prime} 0 \mathrm{E}$; altitude: $138 \mathrm{~m}$ ). Experiments were carried out during seasonal anoestrous (MayJune 2009). The animals were acclimatised to the presence of researchers before the beginning of the experiments to minimise stress. Anoestrous was confirmed by a pattern of persistently low $(<0.5 \mathrm{ng} / \mathrm{ml})$ concentrations of plasma progesterone in blood over four consecutive weeks indicating the absence of functional CLs. Ewes were housed on straw bedding, in pens holding eight to ten ewes. Ewes were isolated for more than 1 month from all contact with rams until their introduction on day 0 of the experiments. At the beginning of the period of exposure to rams, groups of eight to ten ewes were placed in pens with a single sexually active lle-de-France $\times$ Romanov ram. To reduce variability associated with the ram stimulus, rams were rotated among pens every $30 \mathrm{~min}$ for the first $4 \mathrm{~h}$ and then daily until the end of the experiments. 


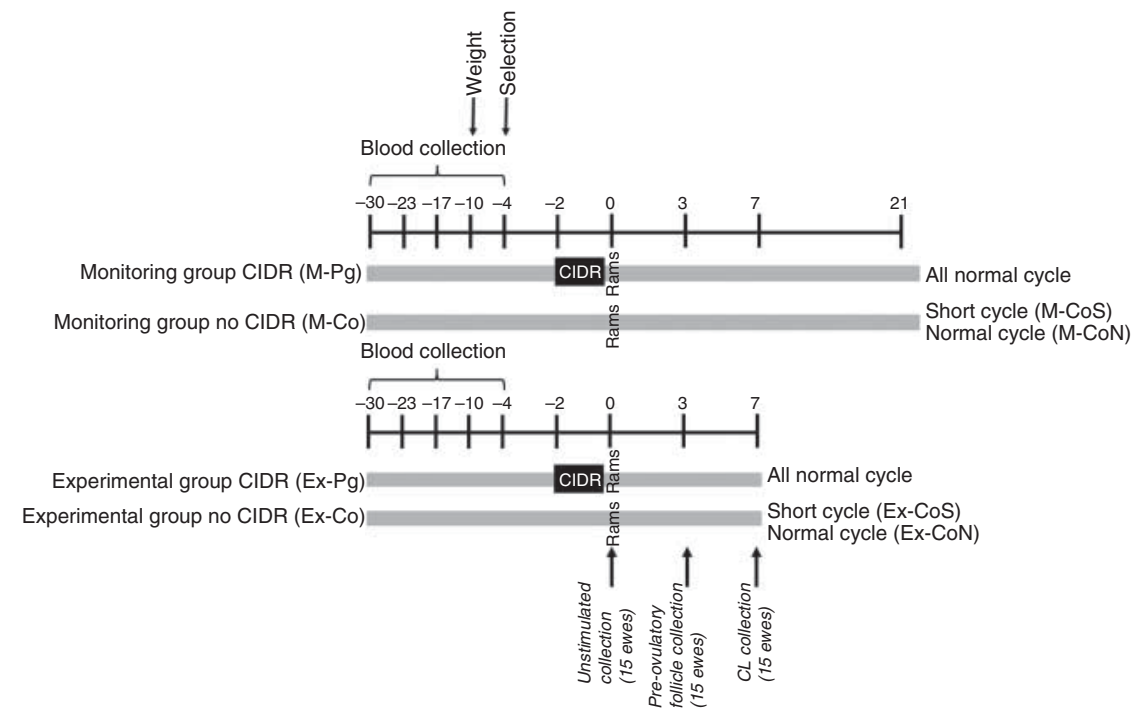

Figure 1 Schematic representation of the experimental protocol. During anoestrous (May-June), 100 ewes were sampled weekly (days $-30,-23$, -17 and -10$)$ for jugular venous progesterone to confirm anoestrous. On day $-4,76$ anoestrous ewes were randomly assigned to an experimental group (Ex; $n=40$ ) or a monitoring group $(\mathrm{M} ; n=36)$. On day -2 , these groups were subdivided into groups that were treated (Ex-P4 and M-P4) or not treated (Ex-Co and M-Co) with intravaginal devices (CIDR) that administered progesterone. The CIDRs were removed 2 days later (day 0 ) and at the same time all ewes were exposed to rams. Ovaries were recovered from the experimental group (Ex-Co and Ex-P4) by ovariectomy at three time points ( 0,3 and 7 days after the 'ram effect'). Jugular venous blood was collected daily until the day of ovariectomy and until day 21 in the monitoring (M-Co and M-P4) groups. A further group of 12 ewes (BS-Co) were sampled daily for 42 days in the breeding season (October-December).

\section{Experimental design}

The experimental protocol is outlined in Fig. 1. The anoestrous experiment had two major elements, an experimental (tissue sampling) group of 40 sheep and a monitoring (nonsampling) group of 36 sheep. Both the experimental group and the monitoring group were from the same pool of animals and they were kept together as a single flock and subjected to the 'ram effect' at exactly the same time and under identical conditions. The monitoring group was required to provide an estimate of the response to the 'ram effect' in the experimental group because the ewes in the experimental group were ovariectomised before their complete ovarian response to the 'ram effect' could be determined. Ewes were selected based on their anoestrous state from an initial flock of 100 ewes. Before exposure to rams on day 0 , the concentration of progesterone was determined in daily blood samples over 4 days (days -4 to -1 ). On day $-2,25$ ewes (ten from the monitoring group defined as M-P4 and 15 from the experimental group defined as Ex-P4) were treated with progesterone using an intravaginal device that released progesterone at a constant rate (CIDR; InterAg, Hamilton, New Zealand), a treatment known to prevent short cycles following the 'ram effect' (Martin et al. 1983, Pearce et al. 1985). The CIDR devices were removed on day 0 . Jugular venous samples of blood were collected daily in the experimental group until the day of ovariectomy and in the monitoring group until day 21 . Ovariectomy was carried out at three time points: on day 0 (before ram exposure, $n=10$; five with and five without progesterone pre-treatment), on day 3 (post-ovulatory, $n=15$; five with and ten without progesterone pre-treatment) and on day 7 (luteal, $n=15$; five with and ten without progesterone pretreatment). Ovariectomy was performed under general anaesthesia through a $5 \mathrm{~cm}$ midline incision by the site veterinary surgeon (J Cognié). Bilateral samples of ovarian venous blood were also collected from the utero-ovarian vein immediately before ovariectomy (and analysed for progesterone only if evidence of ovulation was present). Ovaries were weighed and measured, and follicles and CLs were dissected from the ovaries. Granulosa cells, follicular remnant (mainly theca) and follicular fluid were then isolated (Campbell 1988) and individually snapfrozen for RNA and protein analyses. CLs were divided into four pieces and snap-frozen. Follicles and CLs were also weighed and measured. The largest four follicles were collected from all nonluteal ovaries, but in the presence of CLs, only follicles $>4 \mathrm{~mm}$ were collected. The largest follicle from each ovary (i.e. two follicles per ewe) was chosen for analysis by RT-PCR, two of which were excluded from each group because of the poor quality of the nucleic acid.

In addition, a third group of 12 ewes from the same flock was studied in the breeding season (Fig. 1), designated Bs-Co (October-December 2009). The ewes were habituated and housed under identical conditions as the two groups of ewes in the anoestrous experiment. Samples of jugular venous blood were collected daily for 42 days and analysed for progesterone. The purpose of this group was to determine whether the length of luteal phase in anoestrous ewes induced to ovulate by the 'ram effect' was similar to that in ewes in the breeding season.

\section{Definitions}

A normal cycle was defined as one with a rise in the concentration of progesterone $>0.5 \mathrm{ng} / \mathrm{ml}$ before day 7 (following ram exposure) and was maintained for at least 7 days. The length of the cycle was defined by the number of days between the first rise in the concentration of progesterone 
$>0.5 \mathrm{ng} / \mathrm{ml}$ and that same rise in the next cycle. Within a cycle, the length of the luteal phase was defined as the number of days during which the concentration of progesterone was continuously $>0.5 \mathrm{ng} / \mathrm{ml}$ and that of the follicular phase as the number of days during which the concentration of progesterone was $<0.5 \mathrm{ng} / \mathrm{ml}$ between the end of one cycle and the start of the next cycle. A short cycle was defined by a shortterm (1-6 days) increase in the concentration of plasma progesterone to $>0.5 \mathrm{ng} / \mathrm{ml}$ over the first 7 days following the introduction of rams. Ewes in the monitoring group were referred to as M-P4 (progesterone) and M-Co (control) (Fig. 1). Where cycle length was established, these ewes were designated as M-CoS (short cycle) and M-CoN (normal cycle). Similarly, ewes in the experimental group were referred to as Ex-P4 (progesterone) and Ex-Co (control), and on day 7, when cycle type was able to be established, these ewes were designated as Ex-CoS (short cycle) and Ex-CoN (normal cycle).

\section{Hormone analysis}

The concentration of progesterone was measured by the established ELISA used in the INRA assay laboratory (Chanvallon et al. 2011). The sensitivity of the assay was $0.10 \mathrm{ng} / \mathrm{ml}$. The intra-assay and inter-assay coefficient of variation $(\mathrm{CV})$ values were 8.1 and $6.8 \%$ respectively. The concentration of PGF2 $\alpha$ metabolite (13, 14-dihydro-15-keto prostaglandin; PGFM) of PGF2 $\alpha$ was determined using a commercial EIA Kit (Cayman Chemical Company, Ann Arbor, MI, USA) following the manufacturer's instructions. The intraassay and inter-assay $\mathrm{CV}$ values were 8.8 and $6.8 \%$ respectively, and the sensitivity of the assay was $6.9 \mathrm{pg} / \mathrm{ml}$.

\section{Real-time RT-PCR}

Total RNA was isolated using TRIzol according to the manufacturer's instructions (Invitrogen Life Technologies SAS). Isolated total RNA was then treated with 1 IU DNAse (Qiagen France SAS) as per the manufacturer's instructions. The concentration of RNA was quantified using NanoDrop Technology (ND 1000, Thermo Fisher Scientific, Villebon sur Yvette, France). First-strand cDNA was synthesised from $5000 \mathrm{ng}$ of total RNA using random octamer primers and AMV reverse transcriptase (MP Biomedicals, Illkirch Graffenstaden, France). Gene primers for real-time RT-PCR (Table 1) were designed against published RefSeq mRNA sequences from the NCBI PubMed Database (ovine and bovine sequences) using Primer Express software (PE Applied Biosystems) and synthesised by Eurogentech France SAS (Angers, France). Real-time RT-PCR was carried out in triplicate for each sample on the iCycler iQ Multicolor Detection System (Bio-Rad France). In each reaction, cDNA from $10 \mathrm{ng}$ of total RNA, $0.2 \mu \mathrm{l}$ of forward and reverse primers and $10 \mu \mathrm{l}$ of Bio-Rad SYBR Green Master Mix (Bio-Rad France) and water were added to a final volume of $20 \mu \mathrm{l}$. All primers were used at an optimised concentration of $25 \mu \mathrm{M}$. The PCR conditions were as follows: $50{ }^{\circ} \mathrm{C}$ for $2 \mathrm{~min}, 95^{\circ} \mathrm{C}$ for $10 \mathrm{~min}$, followed by 40 cycles of $95^{\circ} \mathrm{C}$ for $15 \mathrm{~s}$ followed by $60{ }^{\circ} \mathrm{C}$ for $60 \mathrm{~s}$. Single product amplification was confirmed by analysis of disassociation curves and ethidium bromide-stained agarose gel electrophoresis. Controls included the absence of cDNA template or the reverse transcriptase enzyme, in otherwise complete reactions; and each showed no evidence of product amplification or genomic DNA contamination. The expression of all genes was normalised to that of a RPS18 internal loading control that was amplified in parallel for each sample. Results were then expressed relative to the calibrator sample using the $2^{-(\Delta \Delta C T)}$ method (Livak \& Schmittgen 2001).

\section{Statistical analysis}

Data were analysed using software for statistical analysis (SPSS 11.5; SPSS, Inc.). Data on jugular venous concentrations of progesterone and PGFM were analysed using a repeatedmeasures ANOVA run under the general linear model (GLIM). The largest follicle from each ovary and all CLs were analysed. Data on follicular gene expression were analysed by a univariate one-way ANOVA also run under GLIM on individual follicles, with treatment and ovary (i.e. right or left) as fixed factors. Data on luteal gene expression were analysed by a mixed-model ANOVA on individual CLs, with CLs as the repeated measure and treatment as the fixed factor. Post hoc paired comparisons were made when appropriate to do so, using the Bonferroni's correction. Correlations were determined using Pearson's correlation. Data are presented as mean \pm s.E.M.

Table 1 Primer sequences used to detect mRNA expression by real-time RT-PCR.

\begin{tabular}{|c|c|c|c|}
\hline Protein & Gene & Forward $\left(5^{\prime}-3^{\prime}\right)$ & Reverse $\left(5^{\prime}-3^{\prime}\right)$ \\
\hline Ribosomal protein S18 & RPS18 & AGAAACGGCTACCACATCCAA & CCTGTATTGTTATTTTTCGT \\
\hline Vascular endothelial growth factor A & VEGFA & GGATGTCTACCAGCGCAGC & TCTGGGTACTCCTGGAAGATGTC \\
\hline $\begin{array}{l}\text { Vascular endothelial growth factor } \\
\text { receptor } 2\end{array}$ & $K D R$ & CTTCCAGTGGGCTGATGACC & GCAACAAACGGCTTTTCATGT \\
\hline $\begin{array}{l}\text { Vascular endothelial growth factor } \\
\text { receptor } 1\end{array}$ & FLT1 (VEGFR1) & TGGATTTCAGGTGAGCTTGGA & TCACCGTGCAAGACAGCTTC \\
\hline Steroid acute regulatory protein & STAR & CCCATGGAGAGGCTTTATGA & CCCATGGAGAGGCTTTATGA \\
\hline Side-chain cleavage enzyme & CYP11A1 & AGAGAATCCACTTTCGCCACATC & GGTCTTTCTTCCAGGTTCCTGAC \\
\hline $3 \beta$-Hydroxy steroid dehydrogenase & HSD3B1 & GTGAGCTTCCTGCTCAGTCC & СTCСTTGGTTTTCTGCTTGG \\
\hline Androgen receptor & $A R$ & GCCСCTGACCTGGTTTTCA & TTCGGACACACTGGCTGTACA \\
\hline Oestrogen receptor $\alpha$ & ERA1 & GTGCCAGGATTTGTGGATCT & ATTTTCССТGGTTCСTGTCC \\
\hline Progesterone receptor & $P G R$ & GATTCAGAAGCCAGCCAGAG & GATGCTTCATCCССАСАGAT \\
\hline $\begin{array}{l}\text { Lymphatic vessel endothelial } \\
\text { hyaluronan receptor } 1\end{array}$ & LYVE1 & GGCTTCCACGTCTACTCCAC & CCAAACCCAACAGCTTCATT \\
\hline Luteinising hormone receptor & LHCGR & CAGTGTGCTCCTGAACCAGA & GTCTGCAAAGGAGAGGTTGC \\
\hline Prostaglandin F receptor & PTGFR & GСTCСTAGCССТGGGTATTT & TGAGACСТGССТTGTCTGTG \\
\hline
\end{tabular}




\section{Results}

\section{Characterisation of the cycle length following the ram effect}

Because all ewes in the experimental groups (Ex-Co and Ex-P4) were ovariectomised on or before day 7, the lengths of their cycles following the 'ram effect' could not be determined. Therefore, we used an additional monitoring group of animals from the same flock and kept with the experimental groups in a mixed flock and subjected to the 'ram effect' at the same time to determine cycle length (M-Co and M-P4). Of the 36 ewes in the anoestrous monitoring group, ten ewes were excluded: seven because of spontaneous cyclicity not associated with the 'ram effect' and three because they did not respond to the 'ram effect'. Of the remaining sheep ( $n=26$; nine treated with (M-P4) and 19 treated without (M-Co) progesterone), $89 \%$ (8/9) of those in the M-P4 group (treated with progesterone before ram exposure) had a normal cycle compared with $47 \%$ $(9 / 19)$ of the $M-C o$ ewes (not treated with progesterone) $(P<0.01)$.

The patterns of progesterone secretion for the various types of male-induced ovarian cycles were determined in the monitoring groups (M-Co and $\mathrm{M}-\mathrm{P} 4)$ and the breeding season control group (Bs-Co), and they are shown in Fig. 2A. The total length of the cycle was significantly shorter $(P=0.0001)$ in the ewes with short cycles (M-CoS; $6.0 \pm 0.00$ days) than in those with normal cycles during anoestrous (M-CoN; 16.0 \pm

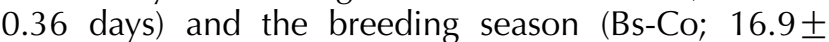
0.23 days; Fig. 2B). The length of the luteal phase was also significantly different $(P=0.0001)$ among the ewes $(\mathrm{M}-\mathrm{CoS}, 2.3 \pm 0.75 ; \mathrm{M}-\mathrm{CoN}, 12.1 \pm 0.43$ and Bs-Co, $14.0 \pm 0.42$ days; Fig. 2C). There was no significant difference in the length of the follicular phase among the ewes $(P=0.380 ; M-C o S, 3.7 \pm 0.75 ; M-C o N, 3.6 \pm 0.33$ and Bs-Co, 3.1 \pm 0.21 ; Fig. 2D). We were able to calculate cycle length and follicular phase length only if a subsequent cycle occurred, and animals that returned to the seasonal anoestrous were not subject to this analysis (Fig. 2C and D).

\section{The short cycle is characterised by low concentrations in jugular and ovarian venous blood and small CLs}

Seven days after the 'ram effect', the jugular venous concentrations of progesterone were lower in the Ex-CoS ewes with short cycles (Fig. 3A) than in those with normal cycles, as expected based on the means for group differentiation. As expected, the pattern of progesterone secretion in all groups was very similar to that observed in the monitoring ewes. In samples collected from Ex-Co ewes not pre-treated with progesterone 3 days after the 'ram effect', the jugular and ovarian venous concentrations of progesterone were variable, suggesting the emergence of two distinct populations of CLs and perhaps reflecting those ewes that would go on to have a normal cycle (Ex-CoN) and a short cycle (Ex-CoS) (Fig. 3B), and similarly, this pattern was observed in their samples of ovarian venous blood (Fig. 3C). This was not the case for Ex-P4 ewes pre-treated with progesterone (Fig. 3B and C). By day 7 following the 'ram effect', the ewes could be classified into Ex-CoN (normal cycle) and Ex-CoS (short cycle), and by day 7 , the jugular venous concentrations of progesterone were lower in the Ex-CoS ewes (Fig. 3D) than in the Ex-CoN ewes. In their ovarian venous samples, the Ex-CoS ewes (with a short cycle) had concentrations of progesterone around a 100-fold or higher, lower $(P<0.0001$; Fig. $3 \mathrm{E})$ than those in the
A
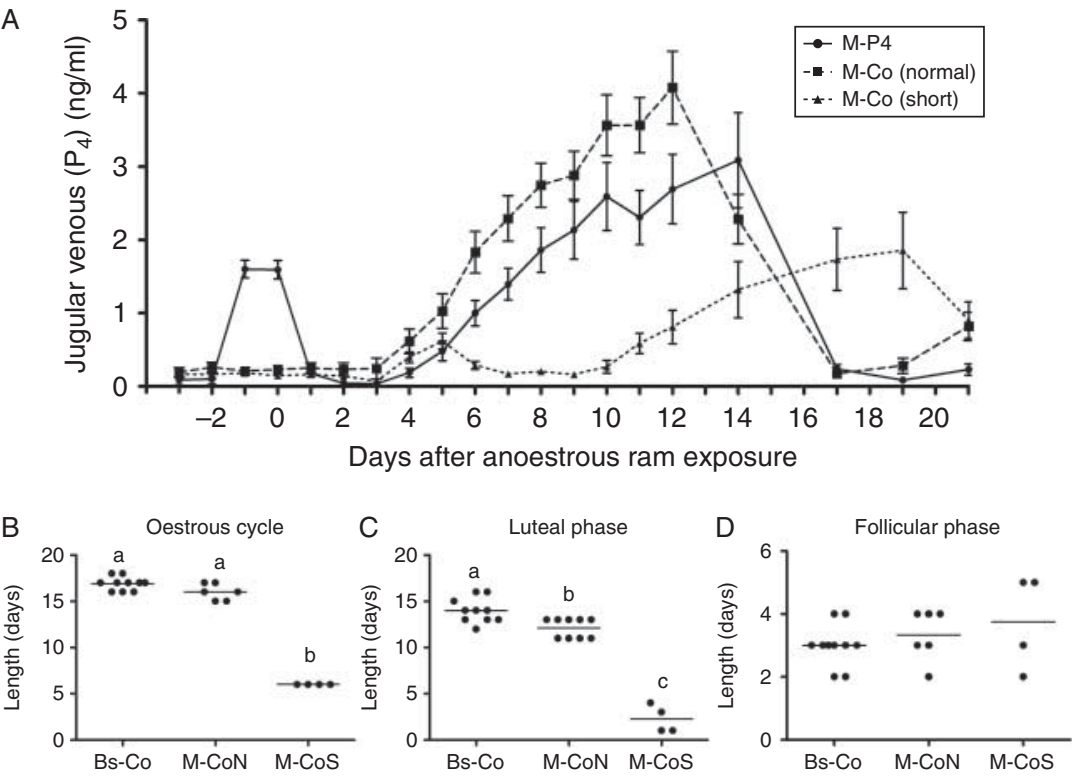

Figure 2 Oestrous cycles of Ile-de-France ewes characterised by their progesterone profiles. (A) Progesterone profiles for the monitoring group of ewes: solid line - M-P4; $n=9$ (NB: all CIDRtreated ewes had normal luteal phases) and dashed line - M-Co (normal), $n=9$ and dotted line $-M-C o$ (short), $n=10$. The lower panels show the lengths of the oestrous cycle (B), the luteal phase $(C)$ and the follicular phase (D) as defined (see text). In (B), (C) and (D), the horizontal lines represent the mean and the dots represent data for individual ewes, and cycle and follicular phase lengths are represented only for the ewes that had a subsequent cycle, i.e. did not return to seasonal anoestrous (M-P4, $n=9 ; \mathrm{M}-\mathrm{Co}$ (normal), $n=7$ and M-Co (short), $n=4)$. Different letters represent statistical significance at $P<0.05$. 
A

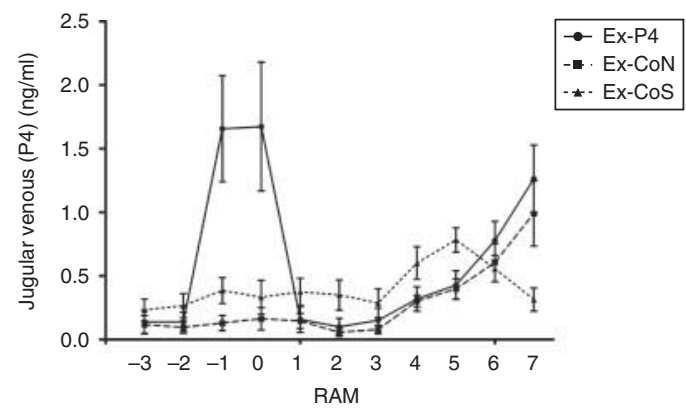

B

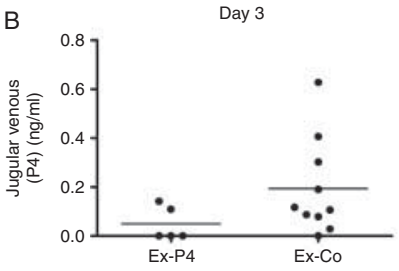

C
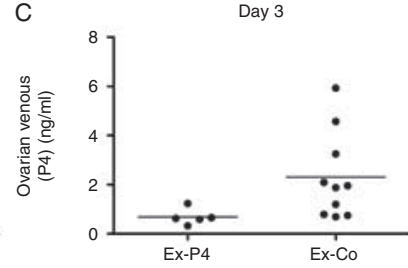

D

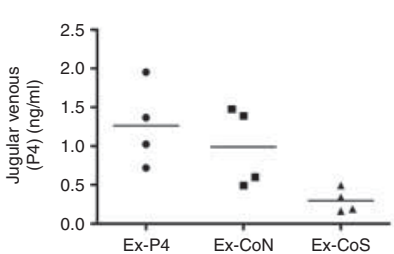

$\mathrm{F}$

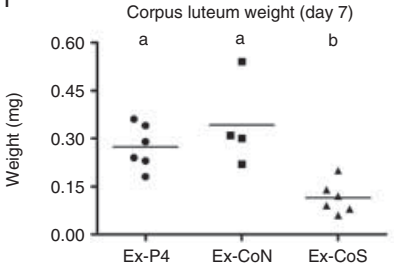

E
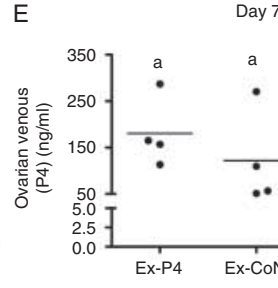

$\mathrm{G}$

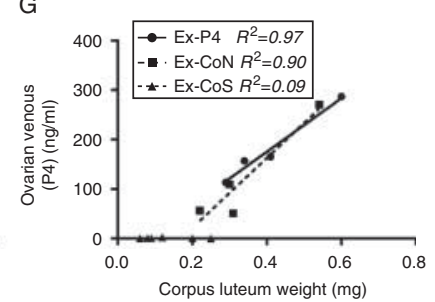

Figure 3 Luteal characteristics of ewes in response to the 'ram effect'. (A) Patterns of progesterone for the experimental groups of ewes: Ex-P4 (solid line), Ex-CoN (dashed line) and Ex-CoS (dotted line). Jugular venous progesterone concentration was measured on day 3 (B) and day 7 (D) and in ovarian venous blood on day 3 (C) and day 7 (E) after the 'ram effect'. Corpus luteum weights were determined on day 7 (F) and regression lines of luteal weight were fitted on the concentration of progesterone in ovarian venous blood $(\mathrm{G})(\mathrm{NB}$, short cycle line is parallel to the $X$ axis). In (B), (C), (D), (E) and (F), the horizontal lines represent the mean and the dots represent data for individual ewes. Different letters (or *) represent statistical significance at $P<0.05$. Data represent those of 15/15 ewes on day 3 and of $12 / 15$ ewes on day 7 , three of which were excluded because of irregular and undefinable progesterone profiles.

Ex-CoN ewes. Additionally, the weight of the CLs was significantly $(P<0.0001)$ lower in the Ex-CoS ewes on day 7 than in the Ex-CoN ewes (Fig. 3F) and, furthermore, luteal weight was correlated with the ovarian venous concentrations of progesterone in all ewes except in the Ex-CoS ewes (Ex-P4, $r=0.97$, $P=0.01 ;$ Ex-CoN, $r=0.90, P=0.04 ;$ and Ex-CoS, $r=0.09, P=0.56$ : Fig. 3G).

On day 3 after the 'ram effect', there were no significant differences in the jugular venous

concentrations of PGFM between the Ex-Co and Ex-P4 ewes (with or without progesterone pre-treatment; Fig. $4 \mathrm{~A}$ and $\mathrm{B}$ ), and the pattern was similar on day 7 (Fig. 4C and D). However, the data for the subgroup of ewes with short cycles (Ex-CoS) were highly variable on day 7 (Fig. 4D). Interestingly, the jugular venous concentrations of PGFM were highly variable in the Ex-CoS ewes, even before the 'ram effect'.

\section{Molecular changes support an early requirement for progesterone}

In ovaries collected from the experimental group ewes before the introduction of rams, pre-treatment with progesterone (Ex-P4) tended to limit follicle size $(P=0.058$; Fig. 5A), but it had no effect on the follicular concentrations of oestradiol (data not shown) or androstenedione (data not shown). When analysing gene expression in granulosa cells isolated from these follicles, we were unable to identify any progesteroneinduced changes in genes involved in the biosynthesis of progesterone (steroid acute regulatory protein (STAR), CYP11A1 and HSD3B1 (HSD3B); Fig. 5B, C and D) and neovascularisation (VEGFA and KDR (VEGFR2); Fig. 5E and $\mathrm{F}), \mathrm{LH}$ receptor gene $(\operatorname{LHCGR}(L H R)$; Fig. 5G) or steroid receptor genes (Fig. $5 \mathrm{H}, \mathrm{I}$ and J). However, we detected a strong trend $(P=0.056)$ towards an increase in the gene expression of STAR in the theca of the Ex-P4 (progesterone-pre-treated) ewes than in those not treated with progesterone (Ex-Co) (Fig. 5K). There were no differences between ewes pre-treated with progesterone and those not pre-treated with progesterone with respect
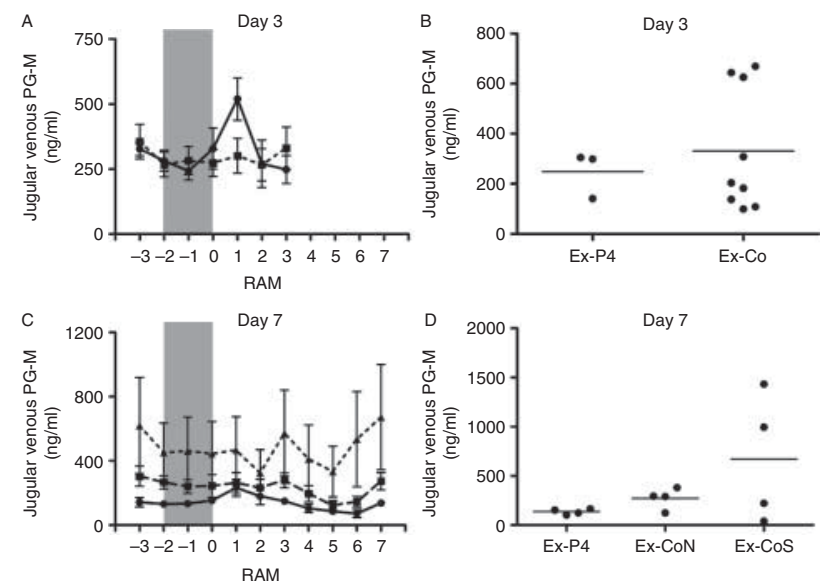

Figure 4 Concentrations of PGFM, the metabolite of PGF $2 \alpha$, in the jugular venous blood of Ile-de-France ewes before and after the 'ram effect'. Concentrations of PGFM in the day 3 group (A) (Ex-P4 (solid line) and Ex-Co (dashed line)) and day 7 group (C) (Ex-P4 (solid line), Ex-CoN (dashed line) and Ex-CoS (dotted line)). In (B) day 3 and (D) day 7 , the concentration of PGFM on the day of ovariectomy is shown. In (B) and (D), the horizontal lines represent the mean and the dots represent data for individual ewes. There were no statistically significant differences. 

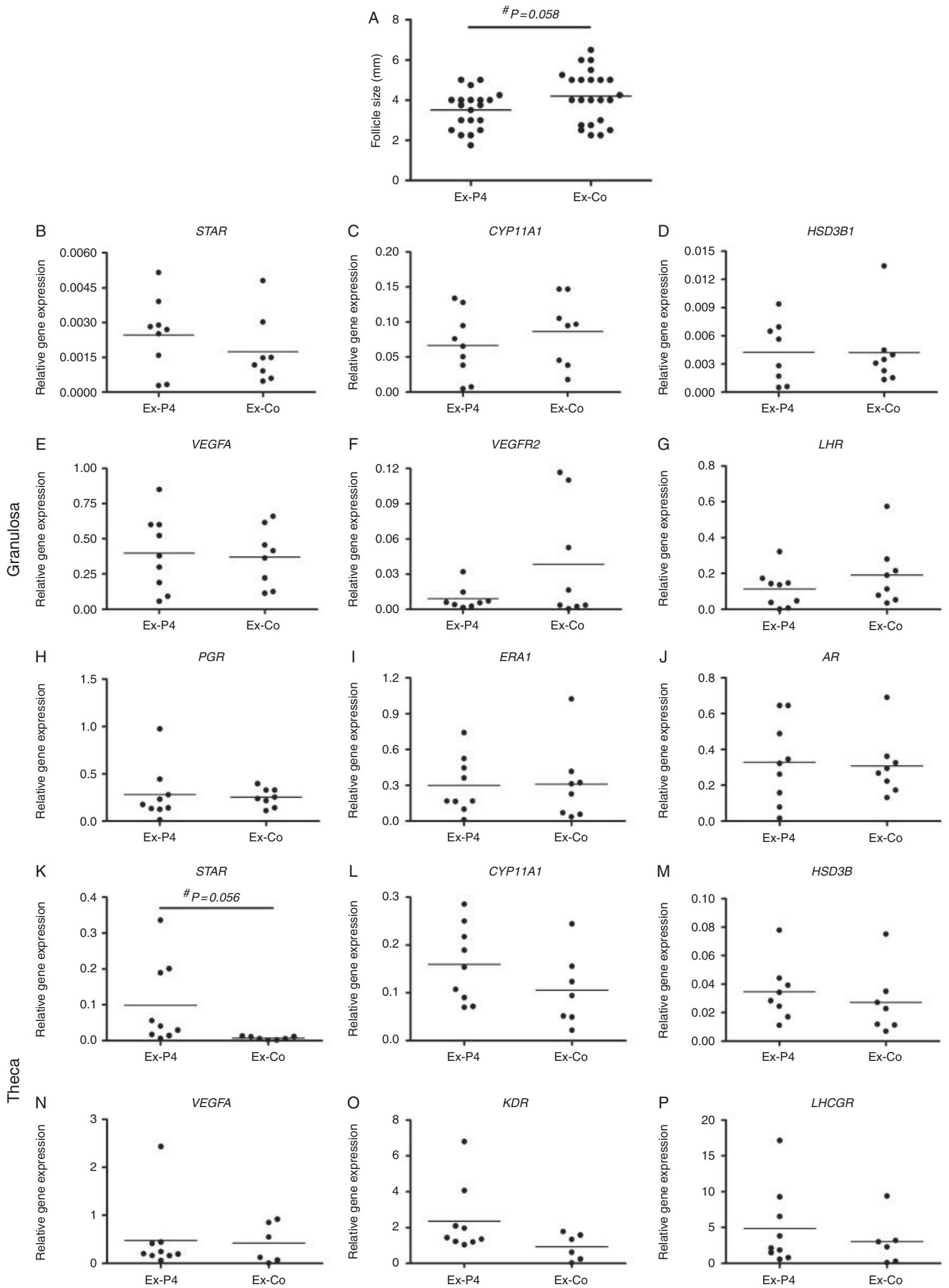

Figure 5 Follicle size (A) and gene expression in granulosa cells (B, C, D, E, F, G, H, I and J) or theca cells (K, L, M, N, O and P) of large follicles in ovaries collected at ovariectomy from anoestrous ewes before the 'ram effect'. Genes involved in progesterone biosynthesis (B, C, D, K, L and M), neovascularisation $(E, F, N$ and $\mathrm{O})$ and steroid hormone signalling $(\mathrm{G}, \mathrm{H}, \mathrm{I}, \mathrm{J}$ and $\mathrm{P})$ were analysed by real-time RT-PCR in granulosa and theca cells. The symbol $\#)$ indicates a trend towards significance $(P<0.10)$. The horizontal lines represent the mean and the dots represent data for individual follicles; $n=8$ follicles per group, each derived from five ewes. 
to the thecal gene expression of CYP11A1, HSD3B1, VEGFA, KDR and LHCGR (Fig. 5L, M, N, O and P).

\section{The first molecular markers of short cycles are those involved in progesterone synthesis and luteal development}

In new CLs or recently ovulated follicles, 3 days following the 'ram effect', there appeared to be a biphasic distribution of gene expression in Ex-Co ewes not pre-treated with progesterone (Fig. 6A, B and C). By day 7 following the 'ram effect' and when we were able to detect changes in the concentrations of progesterone in jugular venous blood that allowed us to identify ewes with short (Ex-CoS) or normal (Ex-CoN) cycles, molecular changes were evident. The expression of all genes involved in progesterone production (STAR, CYP11A1 and HSD3B1) was significantly lower in the CLs of Ex-CoS ewes than in those of the Ex-CoN/Ex-P4 ewes, regardless of pre-treatment with progesterone (Fig. 6D and E). The expression of VEGFA and KDR, both critical for luteal development and luteal vascularisation, was also significantly lower in luteal tissue collected from the Ex-CoS ewes with short cycles (Fig. 6G and H), as was
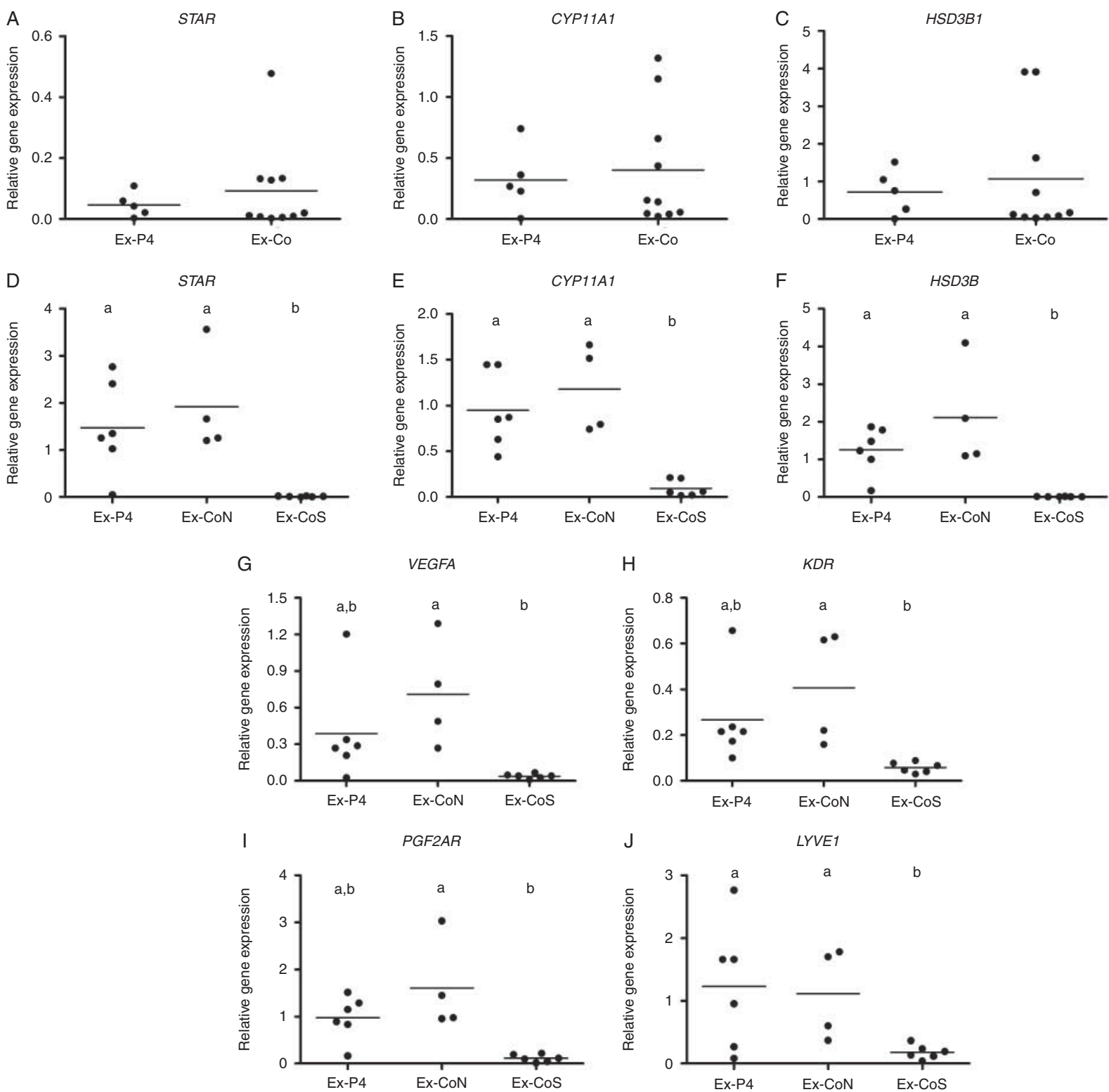

Figure 6 Gene expression in luteal tissue collected on day 3 ( $A, B$ and $C$ ) or day 7 (D, E, F, G, H, I and J) after the 'ram effect'. Genes involved in progesterone biosynthesis (A, B, C, D, E and F), neovascularisation ( $\mathrm{G}$ and $\mathrm{H}$ ) and luteolysis (I and J) were analysed by real-time RT-PCR. The horizontal lines represent the mean and the dots represent data for individual samples. Data represent those of four ewes per group, two of which have multiple ovulations in both the Ex-P4 and the Ex-CoS groups. Different letters represent statistical significance at $P<0.05$. 
that of the lymphatic vascular marker LYVE1 (Fig. 6J). There was also higher expression of $P G F 2 \alpha R$ in the luteal tissue of Ex-CoN ewes with spontaneous normal cycles than in that of Ex-CoS ewes with short cycles (Fig. 6l).

\section{Discussion}

The ability to breed sheep outside of their normal breeding season has always been an important economic objective in sheep farming. Traditionally, this has been accomplished either by cross-breeding with nonseasonal breeds or by the use of hormonal treatments that stimulate reproduction in the non-breeding season. The 'ram effect' is an alternative approach that meets modern criteria for 'clean, green and ethical' production methods (Martin et al. 2004, Martin \& Kadokawa 2006), but its use is limited by poor reliability (Scaramuzzi \& Martin 2008, Chanvallon et al. 2011) and, in particular, by the presence of short cycles that make it difficult to manage breeding programmes (Chemineau et al. 2006). A more complete understanding of the physiological and molecular abnormalities associated with short cycles may help overcome this problem and thus facilitate the more widespread use of the 'ram effect' as an alternative to hormonal treatments. Herein, we provide some molecular insights into the ovarian pathways that may be disrupted in ewes with short cycles.

Theca cells are observed once the follicle has two or more layers of granulosa cells and at about the same time the follicle becomes responsive to $\mathrm{LH}$ and steroidogenesis starts (Richards et al. 2002). In the present study, following pre-treatment with progesterone, we were able to detect early changes in the expression of STAR, a key factor in the pathways of steroidogenesis. However, the expression of $L H C G R$ remained unchanged, suggesting that the follicle's ability to respond to $\mathrm{LH}$ was not enhanced by pre-treatment with progesterone (Fig. 5). Without the synthesis of steroid hormones, including progesterone by the theca, the follicle may not be able to develop into a fully competent pre-ovulatory follicle. Perhaps, short-term treatment with progesterone by stimulating STAR overcomes this and thus allows developing follicles to become fully competent pre-ovulatory follicles.

Interestingly, progesterone did not induce any detectable changes in the expression of any of the genes studied in granulosa cells, suggesting a thecal origin of short cycles. Low thecal expression of STAR may predispose a follicle to dysfunction and thereby induce a short cycle. Although granulosa cells luteinise and form the steroid-producing cells of the functional $\mathrm{CL}$, we speculate that a paracrine interaction involving theca cells leads to the failure of this process in granulosa cells. Curiously, we detected a small but significant difference in follicle size following pre-treatment with progesterone (Fig. 5A). A limitation of our study is the use of expression analysis to examine the components of luteal failure, and moving forward, exploring protein levels and enzymatic activity of these factors will be beneficial.

By day 3 after the 'ram effect' it was not possible to distinguish which ewes were undergoing short cycles but the large variation in gene expression, observed at this time, in the ewes that were not pre-treated with progesterone, suggests the presence of two subpopulations. One with high expression forming a sub-population that would have gone on to have normal cycles and the other sub-population with low expression, as the one that would have gone on to have short cycles. This inability to identify ewes destined to have short cycles before the 'ram effect' or on day 3 after the 'ram effect' emphasises the difficulties inherent in investigating the short cycle. These data suggest that the defect responsible for short cycles is likely to be present at a molecular level by day 3 after the 'ram effect'. By day 7 , ewes with short cycles were readily identified by the concentration of progesterone in jugular venous blood, and in these ewes, there were clear differences in the expression of genes involved in the progesterone biosynthetic pathway in the group of ewes with short cycles. The levels of STAR, CYP11A1 and HSD3B1 were all virtually undetectable and explained the low concentration of progesterone in jugular venous blood in these ewes. There are obvious similarities between the ovine short cycle and human luteal phase insufficiency. Our observations raise the question of whether the ovarian follicular environment could contribute to insufficient luteal phase progesterone production in some infertile women (Hinney et al. 1996). Luteal support in the form of progesterone supplementation is routinely provided during assisted reproductive technologies (Pritts \& Atwood 2002), although no pre-treatments similar to that of our CIDR currently exist.

An alternative hypothesis to explain short cycles proposes that short cycles are the result of premature luteolysis and involve the uterus. Hysterectomised ewes were reported to have a very few or no short cycles (Chemineau et al. 1993, Lassoued et al. 1997), findings that support the premature luteolysis hypothesis. Additionally, inhibition of PGF synthesis with indomethacin reduced, but did not completely suppress, short cycles (Acritopoulou \& Haresign 1980). Interestingly, in our study, the level of the receptor for PGF $2 \alpha R$, which mediates luteolysis, was actually lower in the short-cycle group, and in conjunction with the unchanged concentrations of PGFM, these data contradict the above findings (Acritopoulou \& Haresign 1980, Chemineau et al. 1993, Lassoued et al. 1997) and suggest that the normal luteolytic pathway is not active during the short cycle. Obviously, this is a serious discrepancy that can only be resolved by further experimentation.

The importance of the VEGF system in normal luteinisation is well characterised (Fraser \& Wulff 2003). Modulation of angiogenesis during the luteal phase by 
treatment with inhibitors of VEGFA signalling either at or shortly following ovulation significantly reduced the number of proliferative and endothelial cells within the $\mathrm{CL}$ and significantly decreased progesterone secretion (Wulff et al. 2001c, Hazzard et al. 2002), while a more prolonged treatment, well into the luteal phase, resulted in a complete ablation of microvascular branching (Wulff et al. 2001a, 2001b). Inhibition of LH signalling using GNRH antagonists mimicked this effect, also suppressing early luteal angiogenesis and implicating the LH surge in normal luteal angiogenesis, consistent with the described induction of VEGFA signalling by LH (Koos 1995, Dickson \& Fraser 2000). The in vivo inhibition of VEGFA signalling throughout the luteal phase (days 3-10 in the marmoset monkey) also decreased luteal angiogenesis and the blood concentration of progesterone (Dickson et al. 2001, Wulff et al. 2001c). Recently, a study carried out by Christensen et al. (2012) indicated that treatment with progesterone increased the levels of VEGFA, KDR and angiopoietin 1 (ANGPT1 (ANG1)) in the CL of anoestrous ewes. In our study, the ewes that had an oestrous cycle of normal length, pre-treatment with progesterone had no effect on the levels of these markers of luteal angiogenesis compared with control ewes. However, in our study, all ewes were exposed to the 'ram effect', which may account for the differences between our study and that of Christensen. Nevertheless, both studies suggest the need for appropriate vascular development and remodelling for normal luteal function.

Recently, it has been proposed that there is a subpopulation of macrophages that is capable of promoting vascular development (Venneri et al. 2007, Pucci et al. 2009). In addition to the classic macrophage markers, LYVE1, mannose receptor (MRC1 or CD206) and CD163, there are other lineage-defining markers of the proangiogenic phenotype of macrophages. Most interestingly, it appears that these macrophages are critical for the normal development of the $\mathrm{CL}$, and their loss, achieved using an intricate mouse model of acute macrophage deletion, diminished the expression of the steroidogenic genes, STAR, Cyp11a1 and Hsd3b1 (Care et al. 2013). It is possible that the vascular defect in the $\mathrm{CL}$ during the short cycle has an immunological component, and this hypothesis would account for both the steroidogenic defect and the decrease in LYVE1 expression that we observed and certainly warrants further examination.

Developing 'clean, green and ethical' systems of livestock production requires an in-depth understanding of the underlying physiological mechanisms and of any coincidental aberrant physiology, in our case, the short cycle. The research described herein implicates the theca of the developing follicle in this aberrant process. However, more research is required to confirm or refute these preliminary findings. Future research examining histological changes in the vasculature of the collapsed follicle and the early $\mathrm{CL}$ and in the processes of luteinisation may help to provide further insights into the molecular and cellular defects associated with the short cycle and perhaps ultimately lead to improved efficacy of the 'ram effect' and to better systems for hormone-free methods for breeding sheep outside of the normal breeding season.

\section{Declaration of interest}

The authors declare that there is no conflict of interest that could be perceived as prejudicing the impartiality of the research reported.

\section{Funding}

This research was supported with grants from the Region Centre (No de la convention 200800030333) and the European Union Framework 6 funding programme (MEXC-CT-2006-042499). R J Scaramuzzi was the recipient of an EU Marie Curie Chair of Excellence (MEXC-CT-2006-042499).

\section{Acknowledgements}

The authors thank the staff from the INRA experimental stations at Nouzilly for their help during the study.

\section{References}

Acritopoulou S \& Haresign W 1980 Response of ewes to a single injection of an analogue of PGF- $2 \alpha$ given at different stages of the oestrous cycle. Journal of Reproduction and Fertility 58 219-221. (doi:10.1530/jrf.0. 0580219)

Cahill LP 1981 Folliculogenesis in the sheep as influenced by breed, season and oestrous cycle. Journal of Reproduction and Fertility. Supplement $\mathbf{3 0}$ 135-142.

Care AS, Diener KR, Jasper MJ, Brown HM, Ingman WV \& Robertson SA 2013 Macrophages regulate corpus luteum development during embryo implantation in mice. Journal of Clinical Investigation 123 3472-3487. (doi:10.1172/JCl60561)

Chanvallon A, Sagot L, Pottier E, Debus N, Francois D, Fassier T, Scaramuzzi RJ \& Fabre-Nys C 2011 New insights into the influence of breed and time of the year on the response of ewes to the 'ram effect'. Animal 5 1594-1604. (doi:10.1017/S1751731111000668)

Chemineau P, Daveau A, Locatelli A \& Maurice F 1993 Ram-induced short luteal phases: effects of hysterectomy and cellular composition of the corpus luteum. Reproduction, Nutrition, Development 33 253-261. (doi:10.1051/rnd:19930307)

Chemineau P, Pellicer-Rubio MT, Lassoued N, Khaldi G \& Monniaux D 2006 Male-induced short oestrous and ovarian cycles in sheep and goats: a working hypothesis. Reproduction, Nutrition, Development $\mathbf{4 6}$ 417-429. (doi:10.1051/rnd:2006022)

Christensen AC, Haresign W \& Khalid M 2012 Progesterone exposure of the preovulatory follicle in the seasonally anestrous ewe alters the expression of angiogenic growth factors in the early corpus luteum. Theriogenology 77 1648-1660. (doi:10.1016/j.theriogenology.2011.12.010)

Dickson SE \& Fraser HM 2000 Inhibition of early luteal angiogenesis by gonadotropin-releasing hormone antagonist treatment in the primate. Journal of Clinical Endocrinology and Metabolism 85 2339-2344. (doi:10.1210/jc.85.6.2339)

Dickson SE, Bicknell R \& Fraser HM 2001 Mid-luteal angiogenesis and function in the primate is dependent on vascular endothelial growth factor. Journal of Endocrinology 168 409-416. (doi:10.1677/joe. 0.1680409 ) 
Fraser HM \& Wulff C 2003 Angiogenesis in the corpus luteum. Reproductive Biology and Endocrinology 1 88. (doi:10.1186/ 1477-7827-1-88)

Gordon I 1997 In Controlled Reproduction in Sheep and Goats. Wallingford, Oxon, UK; New York, NY, USA: CAB International.

Hazzard TM, Xu F \& Stouffer RL 2002 Injection of soluble vascular endothelial growth factor receptor 1 into the preovulatory follicle disrupts ovulation and subsequent luteal function in rhesus monkeys. Biology of Reproduction 67 1305-1312. (doi:10.1095/biolreprod67.4.1305)

Hinney B, Henze C, Kuhn W \& Wuttke W 1996 The corpus luteum insufficiency: a multifactorial disease. Journal of Clinical Endocrinology and Metabolism 81 565-570. (doi:10.1210/jc.81.2.565)

Knight TW, Lindsay DR \& Oldham CM 1975 Proceedings: the influence of rams on the fertility of the ewe. Journal of Reproduction and Fertility $\mathbf{4 3}$ 377-378. (doi:10.1530/jrf.0.0430377)

Koos RD 1995 Increased expression of vascular endothelial growth/permeability factor in the rat ovary following an ovulatory gonadotropin stimulus: potential roles in follicle rupture. Biology of Reproduction 52 1426-1435. (doi:10.1095/biolreprod52.6.1426)

Land RB, Baird DT \& Scaramuzzi RJ 1976 Dynamic studies of prostaglandin F-2 $\alpha$ in the utero-ovarian circulation of the sheep. Journal of Reproduction and Fertility 47 209-214. (doi:10.1530/jrf.0.0470209)

Lassoued N, Khaldi G, Chemineau P, Cognie Y \& Thimonier J 1997 Role of the uterus in early regression of corpora lutea induced by the ram effect in seasonally anoestrous Barbarine ewes. Reproduction, Nutrition, Development 37 559-571. (doi:10.1051/rnd:19970507)

Livak KJ \& Schmittgen TD 2001 Analysis of relative gene expression data using real-time quantitative PCR and the $2(-$ Delta Delta $C(\mathrm{~T}))$ method. Methods 25 402-408. (doi:10.1006/meth.2001.1262)

Martin GB \& Kadokawa H 2006 "Clean, green and ethical" animal production. Case study: reproductive efficiency in small ruminants. Journal of Reproduction and Development 52 145-152. (doi:10.1262/ jrd.17086-2)

Martin GB, Scaramuzzi RJ \& Lindsay DR 1981 Induction of ovulation in seasonally anovular ewes by the introduction of rams: effects of progesterone and active immunization against androstenedione. Australian Journal of Biological Sciences 34 569-575.

Martin GB, Scaramuzzi RJ, Oldham CM \& Lindsay DR 1983 Effects of progesterone on the responses of Merino ewes to the introduction of rams during anoestrus. Australian Journal of Biological Sciences 36 369-378.

Martin GB, Oldhan CM, Cognie Y \& Pearce DT 1986 The physiological response of anovulatory ewes to the introduction of rams - a review. Livestock Production Science 15 219-247. (doi:10.1016/ 0301-6226(86)90031-X)

Martin GB, Milton JT, Davidson RH, Banchero Hunzicker GE, Lindsay DR \& Blache D 2004 Natural methods for increasing reproductive efficiency in small ruminants. Animal Reproduction Science 82-83 231-245. (doi:10.1016/j.anireprosci.2004.05.014)

Pearce DT \& Oldham CM 1988 Ovulation in the Merino ewe in the breeding and anoestrous seasons. Australian Journal of Biological Sciences 41 23-26.

Pearce DT, Martin GB \& Oldham CM 1985 Corpora lutea with a short lifespan induced by rams in seasonally anovulatory ewes are prevented by progesterone delaying the preovulatory surge of $\mathrm{LH}$. Journal of Reproduction and Fertility 75 79-84. (doi:10.1530/jrf.0.0750079)
Pritts EA \& Atwood AK 2002 Luteal phase support in infertility treatment: a meta-analysis of the randomized trials. Human Reproduction 17 2287-2299. (doi:10.1093/humrep/17.9.2287)

Pucci F, Venneri MA, Biziato D, Nonis A, Moi D, Sica A, Di Serio C, Naldini L \& De Palma M 2009 A distinguishing gene signature shared by tumor-infiltrating Tie2-expressing monocytes, blood "resident" monocytes, and embryonic macrophages suggests common functions and developmental relationships. Blood 114 901-914. (doi:10.1182/ blood-2009-01-200931)

Richards JS, Russell DL, Ochsner S, Hsieh M, Doyle KH, Falender AE, Lo YK \& Sharma SC 2002 Novel signaling pathways that control ovarian follicular development, ovulation, and luteinization. Recent Progress in Hormone Research 57 195-220. (doi:10.1210/rp.57.1.195)

Scaramuzzi RJ \& Martin GB 2008 The importance of interactions among nutrition, seasonality and socio-sexual factors in the development of hormone-free methods for controlling fertility. Reproduction in Domestic Animals 43 (Suppl 2) 129-136. (doi:10.1111/j.1439-0531.2008.01152.x)

Ungerfeld R, Forsberg M \& Rubianes E 2004 Overview of the response of anoestrous ewes to the ram effect. Reproduction, Fertility, and Development 16 479-490. (doi:10.1071/RD04039)

Venneri MA, De Palma M, Ponzoni M, Pucci F, Scielzo C, Zonari E, Mazzieri R, Doglioni C \& Naldini L 2007 Identification of proangiogenic TIE2-expressing monocytes (TEMs) in human peripheral blood and cancer. Blood 109 5276-5285. (doi:10.1182/blood-2006-10-053504)

Weems YS, Vincent DL, Tanaka Y, Miller-Patrick K, Nusser KD, Ashimine DT, Ledgerwood K, Lee CN \& Weems CW 1992 Effect of prostaglandin F2 $\alpha$ (PGF2 $\alpha$ ) on sources of progesterone and pregnancy in intact, ovariectomized and hysterectomized 90-100 day pregnant ewes. Prostaglandins 43 203-222. (doi:10.1016/0090-6980(92)90090-G)

Weems CW, Weems YS \& Randel RD 2006 Prostaglandins and reproduction in female farm animals. Veterinary Journal $171206-228$. (doi:10.1016/j.tvjl.2004.11.014)

Wulff C, Dickson SE, Duncan WC \& Fraser HM 2001 a Angiogenesis in the human corpus luteum: simulated early pregnancy by HCG treatment is associated with both angiogenesis and vessel stabilization. Human Reproduction 16 2515-2524. (doi:10.1093/humrep/16.12.2515)

Wulff C, Wiegand SJ, Saunders PT, Scobie GA \& Fraser HM 2001b Angiogenesis during follicular development in the primate and its inhibition by treatment with truncated Flt-1-Fc (vascular endothelial growth factor Trap(A40)). Endocrinology 142 3244-3254. (doi:10.1210/ en.142.7.3244)

Wulff C, Wilson H, Rudge JS, Wiegand SJ, Lunn SF \& Fraser HM 2001c Luteal angiogenesis: prevention and intervention by treatment with vascular endothelial growth factor trap(A40). Journal of Clinical Endocrinology and Metabolism 86 3377-3386. (doi:10.1210/jc.86.7. 3377)

Received 23 August 2013

First decision 13 September 2013

Revised manuscript received 28 November 2013

Accepted 19 December 2013 